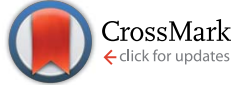

Cite this: J. Anal. At. Spectrom., 2014, 29, 2379

Received 24th July 2014

Accepted 26th September 2014

DOI: $10.1039 / c 4 j a 00244 j$

www.rsc.org/jaas

\title{
Rapid determination of 26 elements in iron meteorites using matrix removal and membrane desolvating quadrupole ICP-MS
}

\begin{abstract}
Xiaoxia Duan $^{\mathrm{abc}}$ and Marcel Regelous ${ }^{\mathrm{a}}$
We describe a rapid and simple method for determination of major and trace elements ranging in concentration from the percent to the parts per billion level in bulk iron meteorites using a quadrupole inductively coupled plasma mass spectrometer (ICP-MS) operated in solution mode. Contamination of samples during the cutting process is avoided by using a laser to cut samples to an appropriate size. Polyatomic interferences derived from the sample matrix, solvents, and Ar gas are reduced using a membrane desolvation sample introduction system. Interferences derived from the iron-rich sample matrix, in particular interferences of iron oxides with isotopes of $\mathrm{Ge}$, are further reduced by removal of Fe from the sample solution using ion exchange prior to measurement. This method allows the precise and accurate measurement of $\mathrm{V}, \mathrm{Cr}, \mathrm{Mn}, \mathrm{Fe}, \mathrm{Co}, \mathrm{Ni}, \mathrm{Cu}, \mathrm{Zn}, \mathrm{Ga}, \mathrm{Ge}, \mathrm{As}, \mathrm{Mo}, \mathrm{Ru}, \mathrm{Rh}, \mathrm{Pd}, \mathrm{Cd}, \mathrm{In}, \mathrm{Sn}, \mathrm{Sb}, \mathrm{Te}$, W, Re, Os, Ir, Pt and Au in iron meteorites. After Fe removal, Ge can be accurately measured in IVA and IVB type iron meteorites having $\mathrm{Fe} / \mathrm{Ge}$ ratios as high as $10^{7}$, with negligible interference from $\mathrm{FeO}$. Samples subjected to the ion-exchange procedure can be measured at a 10 times lower dilution factor, and as a result, it may also be possible to measure the concentrations of those elements which are preferentially partitioned into the silicate mantle of asteroids, and are therefore present in iron meteorites at sub-ppm concentrations.
\end{abstract}

\section{Introduction}

Magmatic iron meteorites are fragments of the metallic cores of asteroids and are among the oldest objects in the Solar System, having formed within 1-2 million years of the condensation of the first solids in the solar nebula 4567 million years ago. ${ }^{1-5}$ Iron meteorites are dominantly composed of $\mathrm{Fe}-\mathrm{Ni}$ alloys (kamacite, taenite), and therefore chemically consist mainly of $\mathrm{Fe}$ and $\mathrm{Ni}$ (about $98 \%$ by weight), with minor amounts of Co, Cr, P, S, and C. Other elements, in particular the highly siderophile (ironloving) elements Pt, Pd, Rh, Ru, Mo, W, Ir and Os are present at the $\mu \mathrm{g} \mathrm{g}^{-1}$ level. Measurements of the concentrations of these trace elements form the basis of the classification scheme whereby the number of iron meteorite parent bodies can be determined.,7 Trace element variations within individual magmatic iron meteorite groups, thought to have been derived from the same parent body, can provide information on the conditions of formation and the processes of crystallization of metallic cores, and can also be used to estimate cooling rates and hence the original size of the asteroid. ${ }^{7,8}$ Trace element

${ }^{a}$ GeoZentrum Nordbayern, Universität Erlangen-Nürnberg, Schloßgarten 5, 91054 Erlangen, Germany

${ }^{b}$ Institute of Geology and Geophysics, Chinese Academy of Sciences, 100029 Beijing, PR China

${ }^{c}$ University of Chinese Academy of Sciences, 100049 Beijing, PR China analysis of iron meteorites therefore provides important insights into the processes of asteroidal core formation and evolution, and may also aid in understanding the formation and composition of the Earth's inaccessible metallic core.

Most of the existing trace element data for iron meteorites were obtained using instrumental or radiochemical neutron activation techniques. ${ }^{9-19}$ These methods have yielded high quality trace element data for several hundred iron meteorites and provided the basis of our current understanding of the processes of asteroid core formation and evolution. However, the neutron activation techniques have several drawbacks: they are time consuming and expensive, and require relatively large samples which afterwards must be treated as radioactive waste. In addition, the number of elements routinely determined by these methods are rather limited (typically less than 15 elements), and several of the highly siderophile elements such as Rh, Pd, Os as well as Re cannot normally be measured. More recently, other methods have been used for analysis of trace elements in iron meteorites, for example Hsu et al. ${ }^{20}$ used an ion microprobe to measure Os, Ir, Pt and Au, but found that other highly siderophile elements $\mathrm{Ru}, \mathrm{Rh}, \mathrm{Pd}$, and Re were below detection limits.

Inductively coupled plasma mass spectrometry (ICP-MS) allows rapid measurement of the concentrations of a large suite of elements, with relatively low detection limits for most elements. A major disadvantage of this technique is the 
presence of polyatomic interferences, which prevent accurate measurement of several important elements. In the case of iron meteorites, formation of ${ }^{56} \mathrm{Fe}^{16} \mathrm{O}^{+},{ }^{58} \mathrm{Fe}^{16} \mathrm{O}^{+}$and ${ }^{56} \mathrm{Fe}^{18} \mathrm{O}^{+}$in the plasma results in interferences with the most abundant isotopes of Ge at masses 72 and 74 in these Fe-rich samples. Interference of ${ }^{58} \mathrm{Ni}^{16} \mathrm{O}^{+}$with ${ }^{74} \mathrm{Ge}$ may also be significant, although Ni makes up less than $10 \%$ of most iron meteorites. These interferences preclude accurate measurement of Ge in iron meteorite types IVA and IVB, which have Ge concentrations of $<1 \mu \mathrm{g} \mathrm{g}^{-1}$, using a conventional quadrupole ICP-MS. ${ }^{21}$ This is a severe disadvantage of this method, because Ge is an important trace element in the classification of iron meteorites. For this reason, most published ICP-MS data for iron meteorites were obtained using high-resolution instruments, which are capable of resolving some of the more problematic interferences. However, other interferences cannot be resolved using even the highest resolution, and in any case high-resolution instruments are relatively expensive and not widely available. The potential of collision or reaction cell technology in reducing problematic interferences during iron meteorite measurements using ICP-MS has not been previously explored.

Separation of individual elements using ion exchange followed by isotope dilution multi-collector ICP-MS has been used for precise measurement of $\mathrm{Re}, \mathrm{Os}, \mathrm{Ru}, \mathrm{Mo}, \mathrm{Pd}$, and $\mathrm{Cd}$ in iron meteorites., ${ }^{\mathbf{1 2 2 - 2 6}}$ Although these methods circumvent the problem of interferences and yield very high precision data, they are time consuming and expensive, requiring complex chemical processing of samples and the use of expensive enriched isotopic spikes, and hence the number of elements that can be determined in this way is limited.

Most iron meteorites are chemically heterogeneous at the millimetre scale, consisting of intergrowths of taenite and kamacite. Much of the published ICP-MS data for iron meteorites were obtained using laser-ablation and high-resolution ICP-MS. ${ }^{25,27-30}$ The high spatial resolution (sub-mm) of the LAICP-MS method allows the composition of individual metal phases, and chemical zoning within the sample at the submillimetre scale to be determined. However, for chemical classification, and for examining the genetic links between samples and the processes of asteroid core formation, a bulk sample analysis is usually preferable. Although bulk sample compositions could be reconstructed from individual laser ablation mineral analyses together with estimates of the mineralogy of the sample, ${ }^{31}$ this is an inaccurate and timeconsuming way to achieve bulk analyses.

We have therefore developed a method for the rapid, accurate and precise measurement of 25-30 trace elements in bulk iron meteorites, which requires only simple chemical processing of the sample and uses a widely available quadrupole ICPMS instrument (Thermo Scientific Xseries2) operated in solution mode.

\section{Experimental}

\subsection{Reagents, samples and standards}

Analytical grade $\mathrm{HNO}_{3}$ (65\%) and $\mathrm{HCl}$ (32\%) from VWR-Merck were purified by sub-boiling distillation in Teflon prior to use.
Suprapur grade HF (40\%) from the same source was used directly as purchased. Acids were diluted to the required concentration with 18.2 M $\mathrm{M}$ Milli-Q water. Sample digestions were carried out in $22 \mathrm{~mL}$ screw-top Teflon beakers from Savillex Corporation (distributed by AHF Analysentechnik, Tübingen, Germany).

Multi-element concentration standards used for external calibration of the ICP-MS were purchased from VHG Labs (Manchester, NH 03103, USA) at concentrations of $100 \mu \mathrm{g} \mathrm{mL}^{-1}$. A $1 \mathrm{~mL}$ aliquot of each was mixed and sequentially diluted with $0.3 \mathrm{M} \mathrm{HNO}_{3}$ and $0.01 \mathrm{M} \mathrm{HCl}$ in order to cover the expected concentration range of samples $\left(0.01\right.$ to $\left.20 \mathrm{ng} \mathrm{g}^{-1}\right)$. Standard solutions were prepared no longer than 48 hours before use. Single element standard solutions of $\mathrm{Be}, \mathrm{Tb}$ and $\mathrm{Th}$ (used as internal standards) and $\mathrm{Fe}$ and $\mathrm{Ni}$ (used for monitoring interferences) were obtained from High Purity Standards (Charleston, SC 29423, USA).

Ion exchange columns for Fe separation were prepared by packing $5 \mathrm{~mL}$ of $50-100 \mu \mathrm{m}$ TRUspec ion exchange resin from Eichrom Technologies LLC (Lisle, IL 60532, USA) into $1 \mathrm{~cm}$ internal diameter polypropylene ion exchange columns from BioRad Laboratories (Hercules, CA 94547, USA).

\subsection{Sample preparation and dissolution}

For solution ICP-MS analysis, samples must be completely dissolved prior to analysis. For preparation of $100 \mathrm{~mL}$ of solution containing $50 \mathrm{mg}$ sample (i.e. dilution factor of 2000), approximately $8 \mathrm{~mm}^{3}$ sample is required. Although smaller samples could be used, effects of sample inhomogeneity will then become more pronounced, and dissolution of larger samples would represent a waste of rare materials, since $<2 \mathrm{mg}$ is actually consumed during an analysis. Our samples were in the form of 10-30 g, 3-5 mm thick slabs, and therefore needed to be cut into small pieces. Initially, we drilled small, approximately 5-10 mg fragments from samples using a steel drillbit, ${ }^{21}$ but found that this introduced significant contamination from the steel, as reflected in far higher measured $\mathrm{W}$ and $\mathrm{V}$ concentrations for samples than previously reported values. This contamination could be reduced but not eliminated, by leaching drilled samples in $\mathrm{HNO}_{3}$ before dissolution. In order to avoid these contamination problems, we therefore cut pieces approximately $50 \mathrm{mg}$ in weight from the interior of large samples using a continuous wave gas $\mathrm{CO}_{2}$ laser (Fig. 1). This method allowed us to avoid existing cut surfaces on the sample, and it neither led to contamination, nor was any loss of potentially volatile elements detected. The laser (wavelength $10.6 \mathrm{~nm}$ ) was operated at a power of $750 \mathrm{~W}$ with a focal spot size of $150 \mu \mathrm{m}$. After cutting, samples were gently cleaned in $0.3 \mathrm{M}$ $\mathrm{HNO}_{3}$ under ultrasound for 15 minutes to remove any surface contamination, then washed in ultrapure water and dried before weighing.

Cleaned samples were accurately weighed and dissolved overnight in $3 \mathrm{~mL} 6 \mathrm{M} \mathrm{HNO}_{3}$ in sealed $22 \mathrm{~mL}$ Teflon beakers at room temperature. Samples were ultrasonicated for 5 minutes at the end of this period. After complete dissolution of the sample, the solution was transferred quantitatively to a 


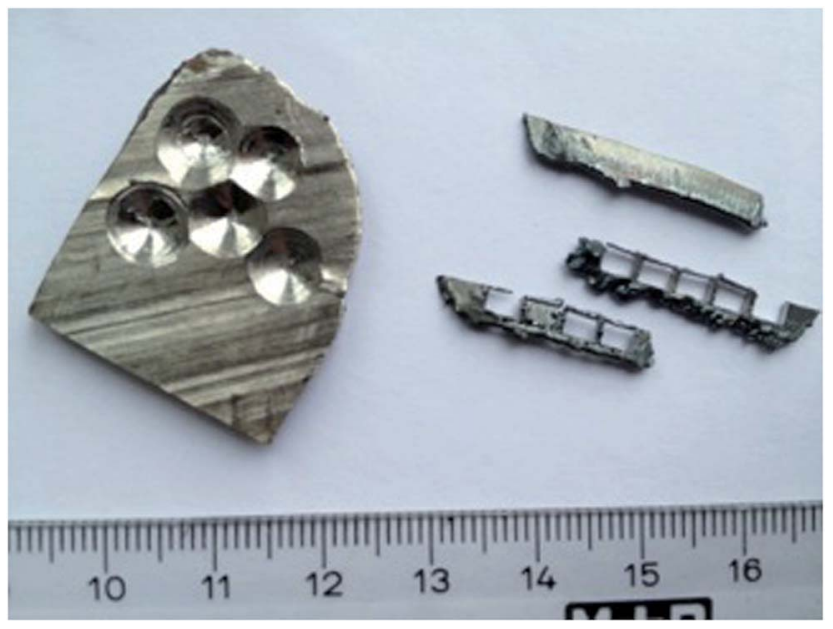

Fig. 1 Photograph of iron meteorite slices, illustrating different sampling methods. Pits were drilled using a hardened steel drillbit to obtain metal shavings (conventional sampling method). Thin slices and approximately $50 \mathrm{mg}$ cubes were cut using the laser in order to avoid contamination from drilling tools. Scale in $\mathrm{cm}$.

second Teflon beaker and weighed, and an approximately $10 \%$ aliquot (Aliquot I, containing $\sim 5 \mathrm{mg}$ dissolved solid) was removed and accurately weighed. This aliquot was processed through ion-exchange columns (see below) for $\mathrm{Ge}, \mathrm{V}, \mathrm{Cr}, \mathrm{Mn}$, $\mathrm{Co}, \mathrm{Cu}$ and $\mathrm{Zn}$ measurements. The remainder (Aliquot II) was diluted with $40 \mathrm{~mL} 0.3 \mathrm{M} \mathrm{HNO}_{3}, 0.2 \mathrm{~mL} 6 \mathrm{M} \mathrm{HCl}$ and $57 \mathrm{~mL}$ $\mathrm{H}_{2} \mathrm{O}$, in order to obtain a final dilution factor of about 2000 , in $0.3 \mathrm{M} \mathrm{HNO}_{3}$ with $0.01 \mathrm{M} \mathrm{HCl}$. The $\mathrm{HCl}$ was added in order to keep highly siderophile elements in solution, but more concentrated $\mathrm{HCl}$ solutions were avoided so as to minimise Cl-based polyatomic interferences. Approximately $5 \mathrm{~mL}$ of the sample solution was transferred to a $15 \mathrm{~mL}$ polypropylene centrifuge tube for measurement, and a second aliquot of 0.5 $\mathrm{mL}$ was diluted to $200 \mathrm{~mL}$ with $0.3 \mathrm{M} \mathrm{HNO}_{3}$ for $\mathrm{Ni}$ analysis.

This dissolution procedure completely dissolves the $\mathrm{Fe}-\mathrm{Ni}$ metal phase, but may not be effective for some accessory minerals that are present in iron meteorites, including silicates, sulphides and phosphides. Although highly siderophile elements will be almost entirely partitioned into the metal, some transition metals, as well as non-siderophile elements may be present in other phases.

\subsection{Removal of Fe using ion exchange}

In order to accurately measure transition metal elements in the Fe mass range ( $\mathrm{Cr}, \mathrm{Mn}, \mathrm{Co}, \mathrm{Cu}, \mathrm{Zn})$, as well as $\mathrm{Ge}$ which suffers from $\mathrm{FeO}$ interferences, we developed a method for removing iron from the sample solution, while quantitatively retaining most other elements of interest. For removal of $\mathrm{Fe}$ from the sample solution, we used Eichrom TRUspec resin, which efficiently retains $\mathrm{Fe}$ in $8 \mathrm{M} \mathrm{HNO}_{3}$ while most other elements including the highly siderophile elements $(\mathrm{Ru}, \mathrm{Rh}$, $\mathrm{Pd}, \mathrm{W}, \mathrm{Os}, \mathrm{Ir}, \mathrm{Pt}, \mathrm{Au}$ ) and transition metals ( $\mathrm{Cr}, \mathrm{Mn}, \mathrm{Co}, \mathrm{Ni}, \mathrm{Cu}$, $\mathrm{Zn}$ ), as well as Re, Ge and Ga have negligible resin-acid partition coefficients in strongly acidic solutions and are therefore not retained on the resin. We determined the resin capacity for Fe in $8 \mathrm{M} \mathrm{HNO}_{3}$ to be about $1.2 \mathrm{mg}$ per $\mathrm{mL}$ of wet resin. Before use, the resin was cleaned using several $10 \mathrm{~mL}$ rinses of $\mathrm{H}_{2} \mathrm{O}$, and then conditioned with $2 \times 5 \mathrm{~mL} 8 \mathrm{M} \mathrm{HNO}_{3}$. Sample Aliquot I was converted to $8 \mathrm{M} \mathrm{HNO}_{3}$ with a few drops of $15 \mathrm{M} \mathrm{HNO}_{3}$ and loaded onto the ion-exhange resin, which was then rinsed 5 times with $2 \mathrm{~mL} 8 \mathrm{M} \mathrm{HNO}_{3}$. The load and rinse solutions were collected in a second Teflon beaker, evaporated to near dryness and redissolved in $2 \mathrm{~mL}$ of $0.3 \mathrm{M}$ $\mathrm{HNO}_{3}$, corresponding to an effective sample dilution factor of 400 . We required $2 \mathrm{~mL}$ of solution to fill the instrument inlet system, but because $90-95 \%$ of the sample matrix of most iron meteorites will be removed during the ion-exchange process, solutions could potentially be analysed at 10-20 times lower dilution factor than Aliquot II, but with the same total dissolved solids of $500 \mu \mathrm{g} \mathrm{g}^{-1}$. After passing samples through the ion exchange columns, Fe concentrations were reduced by approximately 4-5 orders of magnitude. The resin was replaced after each use in order to avoid crosscontamination.

Column yields were determined by passing an accurately weighed $1 \mathrm{~mL}$ aliquot of a $500 \mathrm{ng} \mathrm{g}^{-1}$ solution containing all the elements of interest through the columns, and diluting to $100 \mathrm{~mL}$ with water. Yields for most elements were close to $100 \%$, except for $\mathrm{U}, \mathrm{Th}, \mathrm{Nb}, \mathrm{Ta}, \mathrm{Ti}, \mathrm{Zr}, \mathrm{Hf}$ and the rare earth elements (which were strongly retained on the resin), and Sn, $\mathrm{Pd}$, Mo and $\mathrm{Au}$ (which were partially retained). Of these elements, only Sn, Pd, Mo and Au are present in iron meteorites at significant concentrations, and these elements were therefore determined in sample fraction Aliquot II that had not been passed through the columns. Possible loss of sample due to inefficient recovery from the column materials (as opposed to absorption onto the resin) could be monitored if necessary, by 'spiking' samples with a known amount of an element such as Sr, which is present in iron meteorites in negligible concentrations and which is also not retained on TRUspec resin. Those elements retained on the resin could in theory be recovered by washing the resin with $\mathrm{H}_{2} \mathrm{O}$ after first removing Fe with $1 \mathrm{M} \mathrm{HNO}_{3}$.

Osmium is highly volatile in strongly acidic solution and was therefore partially lost from sample solutions subjected to the ion exchange procedure during the subsequent evaporation step. However, those elements most affected by the high $\mathrm{Fe}$ contents of iron meteorites, i.e. the transition elements in the Fe mass range ( $\mathrm{Mn}, \mathrm{V}, \mathrm{Cr}, \mathrm{Co}, \mathrm{Zn}, \mathrm{Cu})$ and $\mathrm{Ge}$ were quantitatively recovered from the resin and were therefore determined in sample Aliquot I; other elements including Os, Mo, Sn, Pd and Au were determined in Aliquot II. Our sample preparation and analysis procedure is shown schematically in Fig. 2.

Although the cation exchange resin in dilute $\mathrm{HNO}_{3}-\mathrm{HF}$ can be used to separate not only Fe but also Ni from many other elements in Fe-rich samples such as steel alloys, ${ }^{32}$ several important elements $(\mathrm{V}, \mathrm{Mn}, \mathrm{Cr}, \mathrm{Cu}, \mathrm{Zn})$ cannot be separated from Fe by this method. 


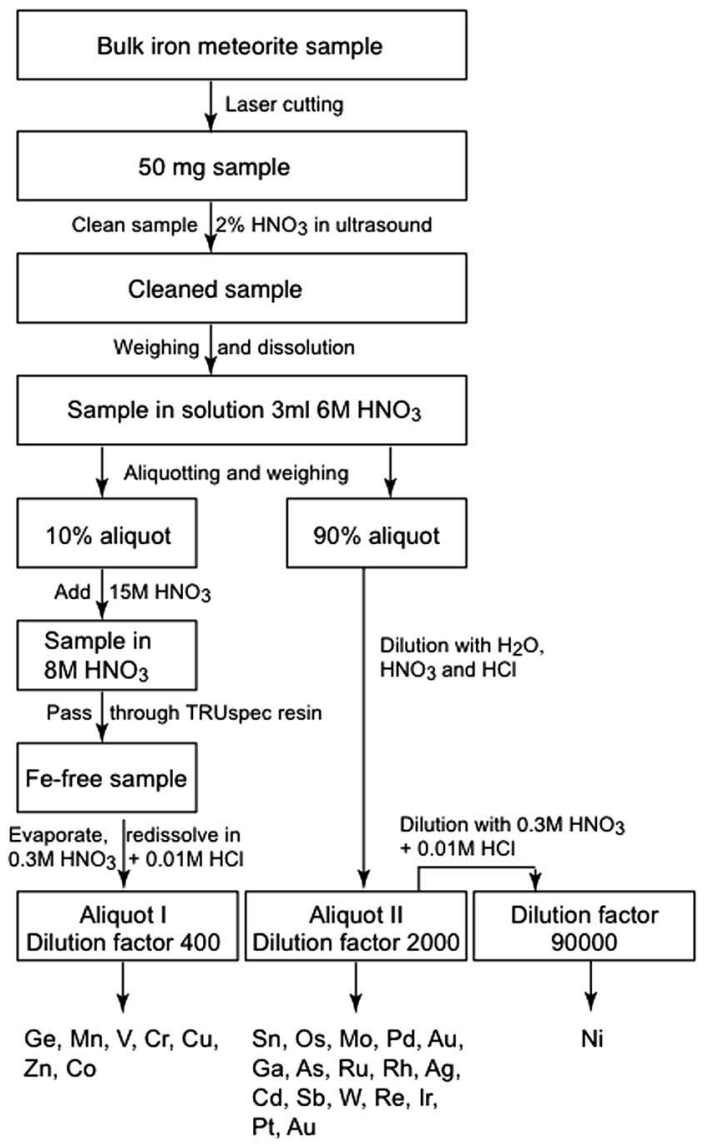

Fig. 2 Schematic of the sample preparation procedure, illustrating treatment of the different sample aliquots prepared for determination of specific elements.

\subsection{Sample introduction system}

Samples were introduced into the mass spectrometer using an SC-2 DX FAST autosampler from Elemental Scientific (Omaha, NE 68122, USA). The autosampler was coupled to either a Peltier-cooled glass Scott-type spray chamber (PC-3 unit, also from Elemental Scientific) equipped with a FAST valve system for rapid sample washout, or a desolvating nebuliser system (Aridus II, from Teledyne Cetac Technologies, Omaha, Nebraska 68144, USA). For measurements made using the Aridus desolvating system, the PFA Teflon nebuliser from the PC-3 unit FAST valve system was connected directly to the Aridus. This required the sample solution to be actively pumped at $50 \mu \mathrm{L} \mathrm{min}{ }^{-1}$ from the sample loop to the nebuliser, rather than passively aspirated by the nebuliser gas flow.

\subsection{Inductively coupled plasma mass spectrometry}

The instrument used for measurements was a Thermo Scientific Xseries2 quadrupole ICP-MS. Typical operating parameters are listed in Table 1. Before each measurement session, the instrument was tuned using a $5 \mathrm{ng} \mathrm{g}^{-1}$ solution of Be, In, Ce, and $\mathrm{U}$ in order to maximize sensitivity in the mid- to high-mass range, whilst maintaining low oxide ratios. The instrument was calibrated using multi-element standard solutions covering the
Table 1 Instrumental operating conditions

\begin{tabular}{|c|c|}
\hline Setting/parameter & Value/description \\
\hline ICP-MS type & Thermo Scientific Xseries 2 \\
\hline RF power & Forward $1380 \mathrm{~W}$ \\
\hline Argon gas flows & $\begin{array}{l}\text { Reflected } 2 \mathrm{~W} \\
\text { Cool gas } 13 \mathrm{~L} \mathrm{~min} \min ^{-1} \\
\text { Auxiliary gas } 0.76 \mathrm{~L} \mathrm{~min}^{-1} \\
\text { Nebuliser gas } 0.7-0.8 \mathrm{~L} \mathrm{~min}^{-1}\end{array}$ \\
\hline Autosampler & Elemental Scientific SC-2 FAST \\
\hline Desolvating system & Cetac Aridus 2 \\
\hline Nebuliser type & Teflon T1H microconcentric \\
\hline Spray chamber & Fluoropolymer, temperature $75{ }^{\circ} \mathrm{C}$ \\
\hline Sample uptake rate & $50 \mu \mathrm{L}_{\min }^{-1}$ \\
\hline Membrane type & Microporous PTFE tubular \\
\hline Sweep gas argon flow & 2.5-3.5 $\mathrm{L} \mathrm{min}^{-1}$ \\
\hline Nitrogen gas flow & $2-3 \mathrm{~mL} \mathrm{~min}^{-1}$ \\
\hline Membrane temperature & $160^{\circ} \mathrm{C}$ \\
\hline Sample cone & Nickel, $1.1 \mathrm{~mm}$ diameter \\
\hline Skimmer cone & Nickel, $0.75 \mathrm{~mm}$ \\
\hline Vacuum & $\begin{array}{l}\text { Expansion stage } 2.2 \times 10^{0} \mathrm{mbar} \\
\text { Intermediate stage } 5.5 \times 10^{-7} \mathrm{mbar} \\
\text { Analyser stage } 6.6 \times 10^{-7} \mathrm{mbar}\end{array}$ \\
\hline Acquisition mode & Scanning \\
\hline Detection mode & Pulse counting \\
\hline Channels per amu & 10 \\
\hline Dwell time & $5-20 \mathrm{~ms}$ \\
\hline Integration time & $225 \mathrm{~s}$ \\
\hline Washout time & $25 \mathrm{~s}$ \\
\hline
\end{tabular}

expected concentration range $\left(0.01-20 \mathrm{ng} \mathrm{g}^{-1}\right)$ in sample solutions. Detectors were cross-calibrated using a $50 \mathrm{ng} \mathrm{g}^{-1}$ solution of about 50 elements covering the entire mass range. In order to correct for instrumental drift, an internal standard solution containing $5 \mathrm{ng} \mathrm{g}^{-1}$ each of $\mathrm{Be}, \mathrm{Tb}$ and Th was mixed with the sample online prior to entering the nebuliser. These elements were chosen as internal standards because they are present in iron meteorites in negligible concentrations, cover the entire mass range, and do not interfere with any of the elements of interest. Corrections for instrument drift were carried out online. Between measurements, the sample introduction system was flushed with $0.3 \mathrm{M} \mathrm{HNO}_{3}$ containing $0.01 \mathrm{M} \mathrm{HCl}$ and $0.05 \mathrm{M} \mathrm{HF}$, which effectively reduced counts at most masses to background. No dissolution of glass components was observed resulting from the use of dilute HF.

For measurements of samples, standards and blanks, dwell times on each mass ranged from 5 to $20 \mathrm{~ms}$, and 45 sweeps across the measured mass range took about 40 seconds. The precision for most elements determined in this way was $1-3 \%$. Due to its percent level concentration in iron meteorites, Fe was not measured directly, but was calculated assuming that Fe and all other elements sum to $100 \%$.

\section{Results and discussion}

\subsection{Reduction of $\mathrm{FeO}$ interferences}

Reduction of the interferences of oxides of $\mathrm{Fe}$ and $\mathrm{Ni}$ with ${ }^{72} \mathrm{Ge}$ and ${ }^{74} \mathrm{Ge}$ is critical to successful trace element measurements of iron meteorites. Our initial experiments were carried out using 
Table 2 Blanks, detection limits and analysis results for samples of the Gibeon meteorite ${ }^{d}$

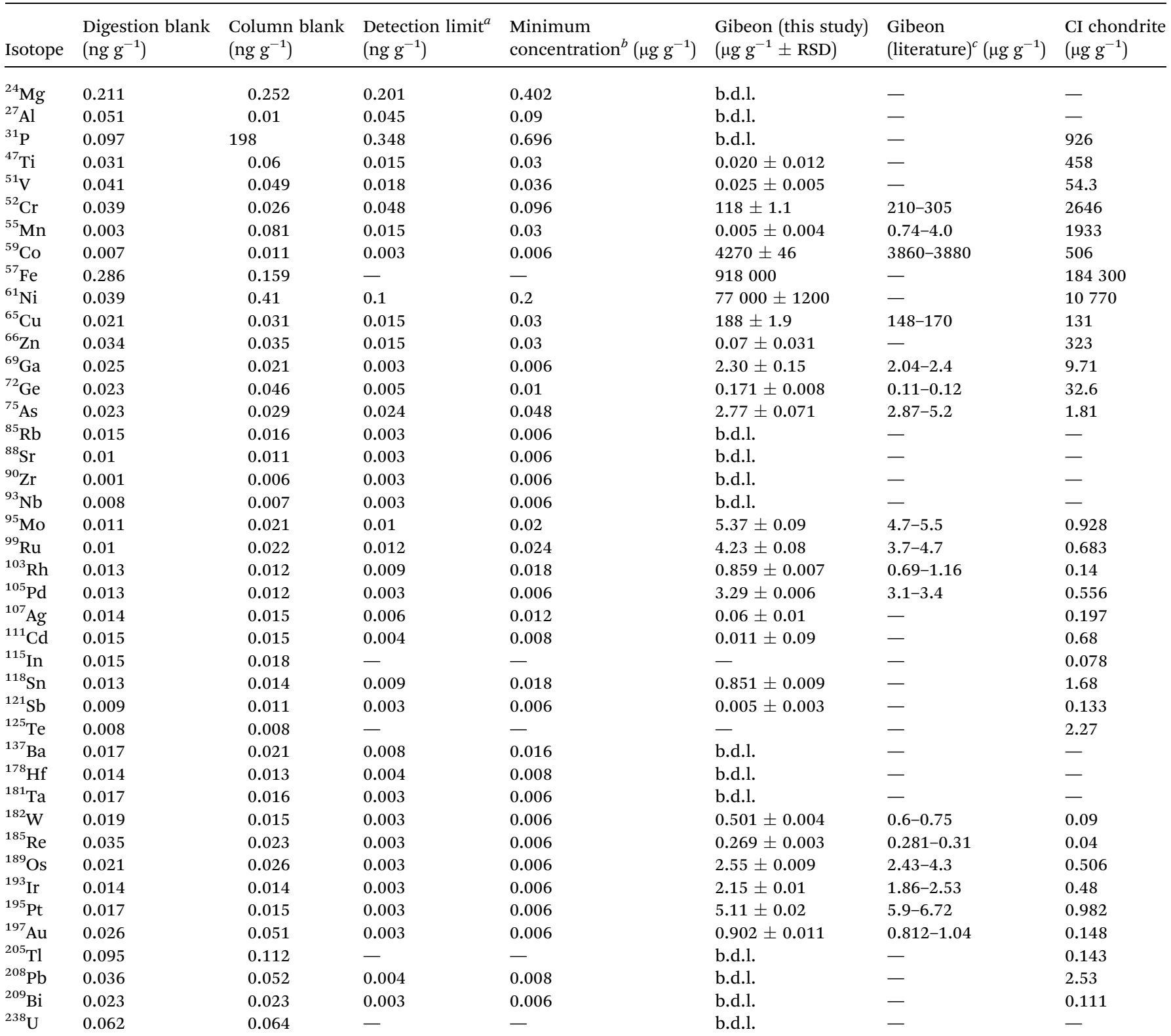

${ }^{a}$ Detection limits calculated as 3 standard deviations of repeated measurements of the digestion blank, or ion exchange blank as appropriate. Detection limits for $\mathrm{Mo}$ and $\mathrm{Ru}$ calculated as 'background' plus 3 standard deviations of measurements of a $\mathrm{Fe}-\mathrm{Ni}$ solution. ${ }^{b}$ Minimum concentrations $\left(\mu \mathrm{g} \mathrm{g}^{-1}\right)$ in samples detectable are calculated from the detection limit assuming a dilution factor of 2000 for elements measured in Aliquot II and a dilution factor of 400 for elements measured in Aliquot I. ${ }^{c}$ Trace element data for Gibeon from the literature using neutron activation, ${ }^{9,12,14,17}$ laser-ablation high-resolution ICP-MS ${ }^{25}$ and quadrupole ICP-MS. ${ }^{21}{ }^{d}$ b.d.l. = below detection limit.

the Peltier-cooled glass Scott type spray chamber. Using this sample introduction system, the $\mathrm{FeO} / \mathrm{Fe}$ ratio, determined by aspirating a solution of pure Fe in $0.3 \mathrm{M} \mathrm{HNO}_{3}$ was $8 \times 10^{-5}$. For comparison, the widely used $\mathrm{CeO} / \mathrm{Ce}$ ratio was approximately 0.014 (i.e. $1.4 \%$ oxide production) under the same instrument conditions. Lower oxide ratios could not be obtained without significantly decreasing the nebuliser gas flow rate, with drastic loss of sensitivity. An $\mathrm{FeO} / \mathrm{Fe}$ ratio of $8 \times 10^{-5}$ corresponds to an ${ }^{56} \mathrm{Fe}^{16} \mathrm{O}^{+} /{ }^{72} \mathrm{Ge}^{+}$ion ratio in the plasma of 0.8 for iron meteorite types having high Ge concentrations $\left(100 \mu \mathrm{g} \mathrm{g}^{-1}\right.$; Fe/Ge about $\left.10^{4}\right)$, and a ratio of 800 in low-Ge iron meteorites $\left(0.1 \mu \mathrm{g} \mathrm{g}^{-1} \mathrm{Ge}\right.$; $\mathrm{Fe} / \mathrm{Ge} 10^{7}$ ), if the samples have not been processed through ion exchange columns.

The XSeries2 ICP-MS is equipped with a collision or reaction cell, which can potentially be used to reduce many polyatomic interferences. Our initial experiments using the glass Scott type spray chamber and the instrument in collision cell mode with a $93 \%$ helium $7 \%$ hydrogen mixture as the collision cell gas showed that we were able to reduce the $\mathrm{FeO} / \mathrm{Fe}$ ratio by approximately an order of magnitude, but with an $80 \%$ loss in 
sensitivity for Ge. We also found that the collision cell voltage potentials could not be optimised for simultaneous reduction of both ${ }^{56} \mathrm{Fe}^{16} \mathrm{O}$ on ${ }^{72} \mathrm{Ge}$ and other potential interferences, such as ${ }^{40} \mathrm{Ar}^{35} \mathrm{Cl}$ with ${ }^{75} \mathrm{As}$ and FeAr species with isotopes of Mo and $\mathrm{Ru}$. In addition, use of the collision cell does not reduce the backgrounds on other transition elements in the Fe mass range (V, Mn, Cr, Cu and $\mathrm{Zn}$ ).

In order to reduce molecular interferences derived from solutions and gas, as well as from the sample matrix, without drastic loss in sensitivity, we used the Aridus II desolvating nebuliser system to dry the sample aerosol prior to injection into the torch. The Aridus Ar sweep gas flow rate was set at 2.32.8 $\mathrm{L} \mathrm{min}^{-1}$, and the $\mathrm{N}_{2}$ gas flow to $2-3 \mathrm{~mL} \mathrm{~min}^{-1}$. Under these conditions, the $\mathrm{Ce} / \mathrm{CeO}$ ratio was above $2000(\mathrm{CeO} / \mathrm{Ce}<0.0005$, or $0.05 \%$ ), and the $\mathrm{FeO} / \mathrm{Fe}$ ratio was reduced to less than $3.6 \times$ $10^{-6}$. The sensitivity for In and U was typically $0.8 \times 10^{8}$ and $2 \times$ $10^{8}$ counts per ppm respectively. Using this sample introduction system without the collision cell, the $\mathrm{FeO} / \mathrm{Fe}$ ratio was reduced to less than $3.6 \times 10^{-6}$ (approximately half of that measured using the collision cell), and with an increase in sensitivity compared to the Scott type spray chamber. However, even with the use of the Aridus the observed $\mathrm{FeO} / \mathrm{Fe}$ ratio of $3.6 \times 10^{-6}$ would preclude measurement of Ge in Group IVA and IVB iron meteorites without ion-exchange processing. These iron meteorite types contain about $0.1 \mu \mathrm{g} \mathrm{g}^{-1} \mathrm{Ge}$, corresponding to a $\mathrm{Fe} /$ Ge ratio of about $10^{7}$, and thus a measured ${ }^{56} \mathrm{Fe}^{16} \mathrm{O} /{ }^{72} \mathrm{Ge}$ ratio of about 40 which is too high for accurate measurement of ${ }^{72} \mathrm{Ge}$. On the other hand, using the desolvating nebuliser and sample aliquots that had been passed through the ion exchange procedure, the interference of ${ }^{56} \mathrm{Fe}^{16} \mathrm{O}$ with ${ }^{72} \mathrm{Ge}$ was $<1 \%$ even for meteorite types having a $\mathrm{Fe} / \mathrm{Ge}$ ratio of $10^{7}$. Measurement of ${ }^{72} \mathrm{Ge}(27.5 \%$ of $\mathrm{Ge})$ rather than ${ }^{74} \mathrm{Ge}(36.3 \%)$ or ${ }^{70} \mathrm{Ge}(20.8 \%)$ allowed us to avoid possible interference of ${ }^{58} \mathrm{Ni}^{16} \mathrm{O}$ on mass 74 , and ${ }^{70} \mathrm{Zn}$ and ${ }^{56} \mathrm{Fe}^{14} \mathrm{~N}$ on mass 70 .

\subsection{Blanks and detection limits}

Instrument response curves calculated from the calibration solutions were required to pass through the 'blank' $0.3 \mathrm{M} \mathrm{HNO}_{3}$ used to dilute the samples. As a result, backgrounds caused by molecular species derived from the solvent and gas are largely corrected for. Using the Aridus and with trace $\mathrm{HCl}$ in sample solutions, interference of ${ }^{40} \mathrm{Ar}^{35} \mathrm{Cl}$ with ${ }^{75} \mathrm{As}$ was negligible (Table 2). Relatively high backgrounds for $\mathrm{Zn}$ and $\mathrm{Sn}$ which are derived from the instrument inlet system, as well as impurities in the $0.3 \mathrm{M} \mathrm{HNO}_{3}$ used to dilute both samples and standards are also theoretically corrected for by this procedure. In contrast, interferences derived from the sample matrix and any contamination introduced during sample processing are not corrected for and must be quantified.

The contamination introduced during sample dissolution and dilution, and during ion exchange column processing was monitored by analysing blanks passed through each procedure. The blank associated with sample dissolution is very small because of the minimal sample processing involved and for most elements not significantly resolved from the $0.3 \mathrm{M} \mathrm{HNO}_{3}$ background. Due to the large volumes of reagents and extra materials used, blanks for the ion exchange procedure are higher than those for dissolution and dilution, but are still insignificant for most elements of interest (Table 2). This is certainly the case for all highly siderophile trace elements, which are present in the Earth's crust at far lower concentrations than in iron meteorites. On the other hand, the blanks for lithophile elements that are present at trace levels in asteroidal cores but make up a major part of terrestrial crustal rocks ( $\mathrm{Si}, \mathrm{Al}$, $\mathrm{Mg}, \mathrm{Ca}, \mathrm{Na}, \mathrm{K}$ ) are too high to allow accurate measurement of these elements in iron meteorites using solution ICP-MS (Table 2). A large $P$ blank for the ion-exchange procedure results from breakdown of the extractant in the TRUspec resin (octylphenyl$N, N$-di-isobutyl carbamoylphosphine oxide) or leakage of finegrained resin particles into the sample. Procedural blanks were subtracted from sample measurements offline.

Detection limits for those elements measured in Aliquot I were calculated as 3 standard deviations of replicates of 10 blank measurements (Table 2). The detection limit for Ge in Fefree solutions is $0.03 \mathrm{ng} \mathrm{g}^{-1}$, allowing accurate analysis of low Ge Group IVA, IVB iron meteorites in Aliquot I containing about $0.25 \mathrm{ng} \mathrm{g}^{-1} \mathrm{Ge}$.

In order to assess the effects of sample-matrix derived interferences in sample solutions which had not been passed through the ion exchange columns (Aliquot II), we also determined the background on all measured masses for a solution of $0.3 \mathrm{M} \mathrm{HNO}_{3}$ containing $400 \mu \mathrm{g} \mathrm{g}^{-1} \mathrm{Fe}$ and $100 \mu \mathrm{g} \mathrm{g}^{-1} \mathrm{Ni}$. This solution was designed to mimic the matrix of an iron meteorite sample solution with a dilution factor 2000, but the experiment was complicated by the presence of trace impurities in the Fe and Ni standard solutions, which become significant at these high $\mathrm{Fe}, \mathrm{Ni}$ concentrations. In addition to the expected high backgrounds in the $\mathrm{Fe}$, Ni mass range and the presence of $\mathrm{FeO}$ and $\mathrm{FeOH}$ around mass $72-75$, slightly elevated backgrounds were also found in the mass range 94-100, likely from FeAr and NiAr. This is supported by the fact that many of these backgrounds could be removed by passing the artificial Fe-Ni solution through the TRUspec resin procedure. These backgrounds derived from the sample matrix cannot be subtracted from the interfered masses without first determining the $\mathrm{FeAr} / \mathrm{Fe}$ and $\mathrm{NiAr} / \mathrm{Ni}$ ratios, which will depend on operating conditions and vary from session to session. However, the only elements of interest in Aliquot II in this mass range are Mo and $\mathrm{Ru}$. Since both ${ }^{57} \mathrm{Fe}^{40} \mathrm{Ar}$ and ${ }^{61} \mathrm{Ni}^{36} \mathrm{Ar}$ could potentially interfere with ${ }^{97} \mathrm{Mo}$ in $\mathrm{Fe}-\mathrm{Ni}$ rich solutions, and since we found that ${ }^{56} \mathrm{Fe}^{40} \mathrm{Ar}<$ ${ }^{58} \mathrm{Ni}^{40} \mathrm{Ar}$ in the 4:1 mixed Fe-Ni solution, we measured ${ }^{95} \mathrm{Mo}$ because ${ }^{57} \mathrm{Fe}^{38} \mathrm{Ar}$ (which is the only possible NiAr or FeAr species with mass 95) is only 13.4 ppm of all FeAr. The detection limit for ${ }^{95} \mathrm{Mo}$ in the Fe-Ni solution (calculated as background

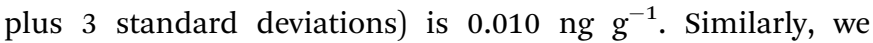
measured ${ }^{99} \mathrm{Ru}$ rather than ${ }^{101} \mathrm{Ru}$ in order to avoid possible interference from ${ }^{61} \mathrm{Ni}^{40} \mathrm{Ar}$, since we found ${ }^{61} \mathrm{Ni}^{38} \mathrm{Ar}$ to be negligible with the detection limit for ${ }^{99} \mathrm{Ru}$ of $0.012 \mathrm{ng} \mathrm{g}^{-1}$ (background plus 3 standard deviations) in the Fe-Ni solution, compared to typical sample solutions (Aliquot II) containing $0.2-0.3 \mathrm{ng} \mathrm{g}^{-1}{ }^{99} \mathrm{Ru}$.

The minimum concentrations of 37 elements that can be detected in iron meteorites using these methods, based on the 


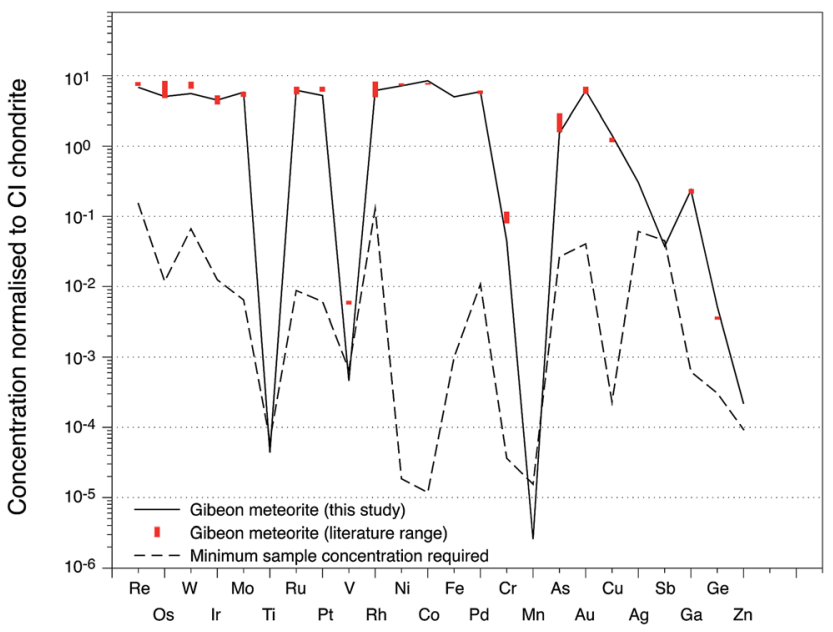

Fig. 3 Concentrations of major, minor and trace elements in the iron meteorite Gibeon, determined in this study (solid line). Red bars show ranges in previously reported values for Gibeon, obtained using instrumental neutron activation and laser ablation high resolution ICPMS. The dashed line shows approximate minimum element concentrations in samples detectable using our method, based on detection limits calculated from the ion-exchange blank (Mn, V, Cr, Co, Zn, Cu, $\mathrm{Ge}$ ), artificial $\mathrm{Fe}-\mathrm{Ni}$ solution (Mo, Ru), or digestion blank (all other elements) at the relevant dilution factor. All data were normalised to $\mathrm{Cl}$ chondrite values (Table 2).

measured detection limits and assuming a dilution factor of either 400 (Aliquot I) or 2000 (Aliquot II) are listed in Table 2.

\subsection{Accuracy and reproducibility}

As a test of our methods, we measured the trace element composition of the iron meteorite Gibeon. This sample was chosen because its trace element composition is well characterised, having been analysed previously using different analytical methods, ${ }^{14,17,21,25}$ and because it has a relatively fine grain size so that the effects of sample inhomogeneity are smaller. In addition, this sample belongs to the iron meteorite group IVA, the members of which have among the lowest Ge concentrations of all iron meteorites, allowing a stringent test of our methods for Ge analysis.

The results of our trace element analysis of Gibeon are presented in Table 2 and Fig. 3. For most elements, the agreement between our analyses and existing literature data is good, and our values lie within the range reported by previous studies. This reported range likely results partly from sample heterogeneity and this effect may also explain the trace element variation we observe between different dissolutions of $50 \mathrm{mg}$ samples of Gibeon (Table 3). This is supported by the fact that we obtained reproducible results for different measurements of the same sample dissolution, run on different days under slightly different operating conditions (Table 3). Another factor which may account for slight differences between our data and literature data obtained by neutron activation methods for the less highly siderophile elements is incomplete dissolution of nonmetal phases during ICP-MS sample preparation, as well as 'nugget effects', resulting from the fact that non-siderophile elements (e.g. $\mathrm{Cr})$ are likely present in rare phases that are widely dispersed within the Fe-Ni metal. In contrast, the highly siderophile elements (e.g. Rh, Ir, Pt) are mainly present in the metal phase and therefore determination of these elements is reproducible between different dissolutions of the same sample (Table 3). Os concentrations determined in Aliquot II (Table 2) lie within the range reported in the literature, indicating that Os, which can be volatile in acidic solutions, was not lost from sample solutions in $\mathrm{HNO}_{3}$ at room temperature.

The elements in Fig. 3 are listed in the order of increasing volatility (decreasing condensation temperature in the solar

Table 3 Results of repeat analyses of different digestions of the Gibeon iron meteorite ${ }^{a}$

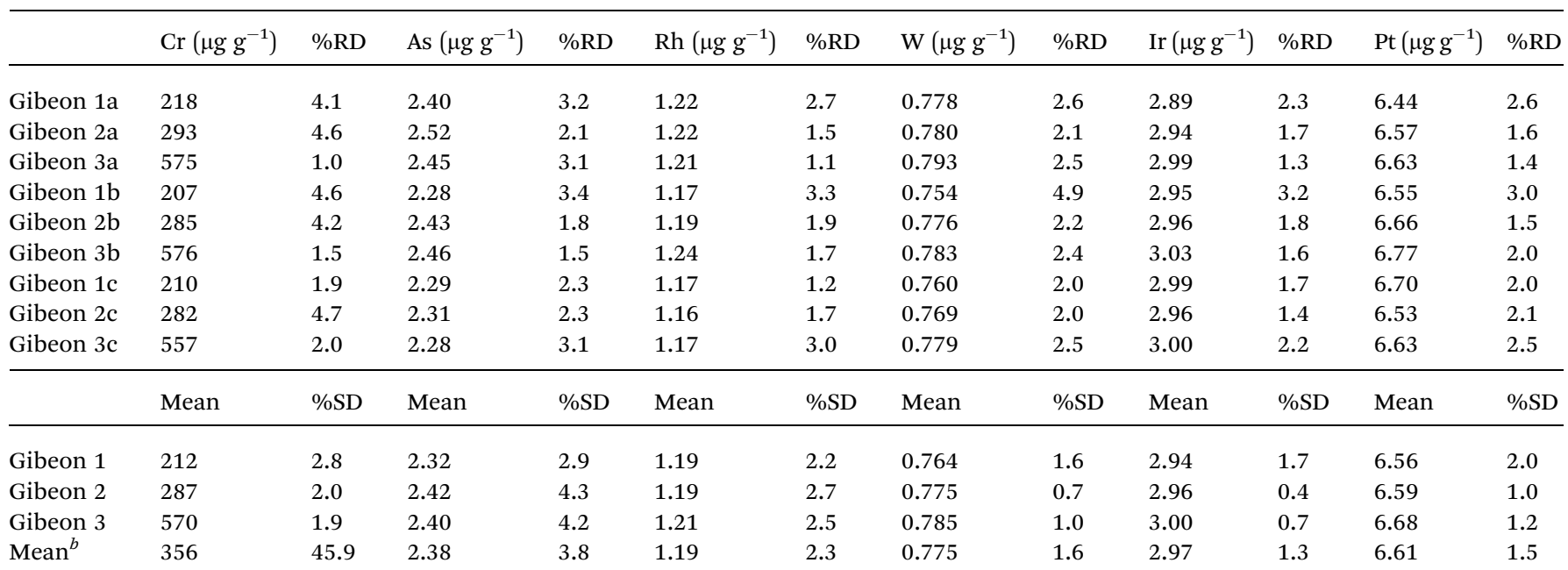

${ }^{a}$ Gibeon 1, 2 and 3 represent dissolutions of three separate $50 \mathrm{mg}$ samples of Gibeon. Three separate measurements of each solution (a, b, c) were carried out on different days under slightly different instrument operating parameters. ${ }^{b}$ Mean of all analyses. 
nebula). Our results are therefore in agreement with existing data that show that more volatile elements (Zn, Ge, Ga, Sb) are depleted in asteroid cores during accretion and differentiation, compared to their abundance in chondritic materials. The low relative abundances of $\mathrm{Ti}, \mathrm{V}$ and $\mathrm{Mn}$ reflect the fact that these elements are partitioned into silicates rather than metals during core formation. The concentrations of these elements in Gibeon are below detection limits and thus represent maximum values.

Detection limits for many non-siderophile elements are low enough that the very low concentrations of these elements might also be determined in iron meteorites, especially in sample solutions from which $\mathrm{Fe}$ has been removed by ionexchange. For example, the Earth's metallic core has been suggested to be a significant reservoir of $\mathrm{Nb}, \mathrm{Pb}$, and rare-earth elements, and analysis of these elements in iron meteorites together with information on metal silicate partitioning under different $P-T$ conditions could be used to test these hypotheses. ${ }^{33}$ Since $\mathrm{Nb}$ and the rare-earth elements can be separated from both $\mathrm{Fe}$ and $\mathrm{Ni}$ using TRUspec resin, provided these elements can be quantitatively recovered from the resin, it may be possible to preconcentrate $\mathrm{Nb}$, Ta and the rare-earth elements by several orders of magnitude, allowing accurate measurement despite the sub-ng $\mathrm{g}^{-1}$ concentrations of these elements in iron meteorites. ${ }^{33}$

\section{Conclusions}

Our new method allows rapid, accurate measurement of a wide range of trace elements in bulk iron meteorites, together with Fe and $\mathrm{Ni}$, using a widely available quadrupole ICP-MS instrument. The combination of Fe removal using ion-exchange together with a desolvating nebuliser sample introduction system allows interference-free analysis of the important element Ge even in low-Ge meteorite types, together with transition metals, Re, Ga, $\mathrm{As}$ and $\mathrm{Sb}$ as well as the highly siderophile elements $\mathrm{Pt}, \mathrm{Pd}, \mathrm{Rh}$, $\mathrm{Ru}, \mathrm{Mo}, \mathrm{W}, \mathrm{Ir}, \mathrm{Au}$ and Os. Our method is less time-consuming than the conventional neutron activation methods, and allows determination of a wider range of trace elements.

Our analytical methods could also be used for analysis of other Fe-rich sample types, for example determination of impurities in industrial iron or steel, or trace element measurement of metal archeological artifacts for source tracing.

\section{Acknowledgements}

We thank Sasia Eiselen of the Bayerisches LaserZentrum in Erlangen for laser cutting of meteorite samples, Tobias Herderich for the initial work in setting up this method, and Melanie Hertel, Stefan Krumm and Christoph Weinzierl for support in the lab.

\section{References}

1 D. L. Cook, R. J. Walker, M. F. Horan, J. T. Wasson and J. W. Morgan, Geochim. Cosmochim. Acta, 2004, 68, 14131431.
2 T. Kleine, K. Mezger, H. Palme, E. Scherer and C. Münker, Geochim. Cosmochim. Acta, 2005, 69, 5805-5818.

3 A. Schersten, T. Elliott, C. J. Hawkesworth, S. Russell and J. Masarik, Earth Planet. Sci. Lett., 2006, 241, 530-542.

4 C. Burkhardt, T. Kleine, B. Bourdon, H. Palme, J. Zipfel, J. Friedrich and D. Ebel, Geochim. Cosmochim. Acta, 2008, 72, 6177-6197.

5 L. P. Qin, N. Dauphas, M. Wadhwa, J. Masarik and P. E. Janney, Earth Planet. Sci. Lett., 2008, 273, 94-104.

6 H. Haack and T. J. McCoy, Treatise Geochem., 2004, 1, 325345.

7 N. L. Chabot and H. Haack, Meteorites and the Early Solar System II, University of Arizona Press, 2006, pp. 747-771.

8 J. I. Goldstein, E. R. D. Scott and N. L. Chabot, Chem. Erde, 2009, 69, 293-325.

9 J. H. Crocket, Geochim. Cosmochim. Acta, 1972, 36, 517-535.

10 E. Pernicka and J. T. Wasson, Geochim. Cosmochim. Acta, 1987, 51, 1717-1726.

11 J. T. Wasson, X. Ouyang, J. Wang and E. Jerde, Geochim. Cosmochim. Acta, 1989, 53, 735-744.

12 D. E. Ryan, J. Holzbecher and R. R. Brooks, Chem. Geol., 1990, 85, 295-303.

13 J. T. Wasson, H. Huber and D. J. Malvin, Geochim. Cosmochim. Acta, 2007, 71, 760-781.

14 M. Hoasli, R. R. Brooks and R. D. Reeves, Chem. Geol., 1993, 106, 207-218.

15 B.-G. Choi, X. Ouyang and J. T. Wasson, Geochim. Cosmochim. Acta, 1995, 59, 593-612.

16 J. T. Wasson, Geochim. Cosmochim. Acta, 1999, 63, 28752889.

17 J. T. Wasson and J. W. Richardson, Geochim. Cosmochim. Acta, 2001, 65, 951-970.

18 J. T. Wasson and G. W. Kallemeyn, Geochim. Cosmochim. Acta, 2002, 66, 2445-2473.

19 J. T. Wasson and W. H. Choe, Geochim. Cosmochim. Acta, 2009, 73, 4879-4890.

20 W. Hsu, G. R. Huss and G. J. Wasserburg, Geochim. Cosmochim. Acta, 2000, 64, 1133-1147.

21 M. D'Orazio and L. Folco, Geostand. Newsl., 2003, 27, 215225.

22 N. Dauphas, B. Marty and L. Reisberg, Astrophys. J., 2002, $565,640-644$.

23 R. J. Walker, W. F. McDonough, J. Honesto, N. L. Chabot, T. J. McCoy, R. D. Ash and J. J. Bellucci, Geochim. Cosmochim. Acta, 2008, 72, 2198-2216.

24 M. E. Wieser and J. R. Laeter, Int. J. Mass Spectrom., 2009, 286, 98-103.

25 T. J. McCoy, R. J. Walker, J. I. Goldstein, J. Yang, W. F. McDonough, D. Rumble, N. L. Chabot, R. D. Ash, C. M. Corrigan, J. R. Michael and P. G. Kotula, Geochim. Cosmochim. Acta, 2011, 75, 6821-6843.

26 T. S. Kruijer, P. Sprung, T. Kleine, I. Leya and R. Wieler, Lunar Planet. Sci., 2013, 44, 1980 (abstract).

27 T. Hirata and R. W. Nesbitt, Earth Planet. Sci. Lett., 1997, 147, 11-24.

28 A. J. Campbell and M. Humayun, Anal. Chem., 1999, 71, 939946. 
29 A. J. Campbell and M. Humayun, Geochim. Cosmochim. Acta, 2005, 69, 4733-4744.

30 E. Mullane, O. Alard, M. Gounelle and S. Russell, Chem. Geol., 2004, 208, 5-28.

31 M. I. Petaev and S. B. Jacobsen, Meteorit. Planet. Sci., 2004, 39, 1685-1697.
32 T. Tindemans, A. Dobney, D. Wanbeke and F. Vanhaecke, J. Anal. At. Spectrom., 2014, 29, 1073-1081.

33 K. P. Jochum, H. M. Seufert, B. Spettel and H. Palme, Geochim. Cosmochim. Acta, 1986, 50, 1173-1183. 